\title{
Introduction: passing, imitations, crossings
}

\author{
MONIQUE ROONEY
}

When it was revealed that Anglo-Australian writer Helen Darville had passed as Ukrainian to publish a novel about the Holocaust, there was much public and scholarly debate about the nature of identity and the meaning of multiculturalism. ${ }^{1}$ Such 'passing' controversies have the capacity to unsettle everyday perceptions about personhood and about social classifications and identifications. The essays collected in this special issue of Humanities Research, 'Passing, Imitations, Crossings', explore the theme and act of 'passing' in a range of social, historical and cultural contexts. Put simply, passing is a type of border crossing, one that normally involves a movement from social disadvantage to advantage or from a socially stigmatised position to one that grants some privilege, or at least allows avoidance or evasion of group classification. Passing is distinct from other identity performances in that it generally refers to a surreptitious transgression of widely accepted social practices. That is, the passer normally masks the fact of his or her 'true' identity - he or she might rely on subterfuge or might remove him or herself from a telling context or simply suppress information that might lead to disclosure of his or her identity-in order to cross social boundaries. In the case of African-Americans, passing for white historically entailed crossing the social divide that separated black and white according to changing cultural, scientific and legal measurements of what constituted racial identity. As St Clair Drake and Horace R. Cayton observed in their study of African-American social life in Chicago's South Side in the 1930s, 'there are thousands of Negroes whom neither colored nor white people can distinguish from full-blooded whites, it is understandable that in the anonymity of the city many Negroes "pass for white" daily, both intentionally

\footnotetext{
1 For scholarship on the Darville/Demidenko affair, see, for instance: Egan, Susanna 2004, 'The company she keeps: Demidenko and the problems of imposture in autobiography', Australian Literary Studies, vol. 21, no. 4 (October), pp. 14-27; Mycak, Sonia 2004, 'Demidenko/Darville: a Ukrainian-Australian point of view', Australian Literary Studies, vol. 21, no. 4 (October), pp. 111-33; Vice, Sue 2006, 'Scandalous fictions: the twentieth-century novel in the public sphere', in Jago Morrison and Susan Watkins (eds), Palgrave Macmillan, Basingstoke, UK, pp. 172-86; Simic, Zora 2007, 'The wog in the room: on the Demidenko controversy then and now', Overland, no. 187 (Winter), pp. 38-41; Takolander, Maria and McCooey, David 2004, 'Fakes, literary identity and public culture', Journal of the Association for the Study of Australian Literature, vol. 3, pp. 57-65; Peres Da Costa, Suneeta 2002, 'Tautological modernity: democracy, magic and racism in the DemidenkoDarville affair', Cultural Studies Review, vol. 8, no. 1 (May), pp. 72-92; Wark, McKenzie 1997, 'The Demidenko effect and the virtual republic', Continuum (Perth), vol. 11, no. 2, pp. 61-71.
} 
and unintentionally' ${ }^{2}$ The prospect of passing multiplies in societies in which the often anonymous flow of people sets the scene for opportunism, masquerade and other forms of role-playing. There are women who have cross-dressed as male to publish books or participate in war and gays and lesbians who have passed as straight to avoid homophobia. There are those who pass out of necessity, to escape war or life-threatening discrimination, and those who pass for greater gain or simply for the thrill of experiencing life on the 'other side', as passing provides the opportunity to temporarily or permanently depart from a designated identity.

The transport and communications revolution that took place in the United States at the end of the nineteenth and in the early decades of the twentieth centuries - a time also of great movement and mixing of diverse social groups in American cities, as well as a period of new strictures and the terrors of lynching - created a fertile context for passing. The many fictional and sociological recordings of African-Americans who 'passed as white' to cross the colour line, from the middle of the nineteenth century through to the 1950s and 1960s - when African-Americans began to win civil rights - suggests how prevalent the act was in a US context. In his encyclopedic study of 'inter-racial' themes in US history, Werner Sollors differentiates the passer from the parvenu (the social climber or upstart). While the act of passing potentially encompasses 'the crossing of any line that divides social groups'3 — and Everett V. Stonequist argues that 'passing is found in every race situation where the subordinate race is held in disesteem ${ }^{\prime 4}$ - Sollors' study locates the phenomenon firmly in US social history. In particular, Sollors connects passing with the burden of racial ancestry for the descendents of slaves. While the general expectation is that newly arrived immigrants will gradually assimilate, the descendents of slavesin what Sollors calls America's 'hypodescent' system - have been treated as members of a caste. African-Americans have been subject to a form of 'ancestorcounting' that reduces personhood to a racial part. ${ }^{5}$

It is for these reasons that Sollors labels passing an 'Americanism'. And this classification accords with the Websters Dictionary (Third edition) definition of passing as 'the act of identifying oneself or accepting identification as a white person - used of a person having some Negro ancestry'. That such classifications are, however, partial and anachronistic is exemplified when Sollors notes that a definition of passing as a border crossing does not appear in the first edition

\footnotetext{
2 St Clair, Drake and Cayton, Horace R. [1945] 1993, Black Metropolis: A study of Negro life in a northern city, University of Chicago Press, p. 159.

3 Sollors, Werner 1997, 'Passing; or sacrificing a parvenu', Neither Black Nor White Yet Both: Thematic explorations of interracial literature, Oxford University Press, New York, p. 257.

4 Stonequist, Everett V. 1937, The Marginal Man: A study in personality and culture conflict, C. Scribner's Sons, New York, p. 199.

5 Sollors, 'Passing; or sacrificing a parvenu', p. 249.
} 
of the Oxford English Dictionary. ${ }^{6}$ Although the $O E D$ 's definition of passing as 'the fact of being accepted, or representing oneself as, a member of a different ethnic, religious, or sexual group' is more general, there are three etymological uses of the term cited, only one of which is British. The other three examples are drawn from American sources, the first of which is Carl Van Vechten's novel Nigger Heaven (1926). Passing operates, in Van Vechten's popular 1920s 'novel of negro life', as shorthand for 'passing for white'. Recently, the popular Internet resource Wikipedia also defines passing largely in terms of US cultural history, suggesting the extent to which US global imperialism inflects everyday cultural understandings, as well as the power of information technologies to shape everyday definitions and the ways in which we understand our own identities and interactions. ${ }^{7}$

To classify passing purely in terms of a US socio-historical context, however, belies the mobile, metaphorical implications of a term that itself signifies evasion of classification or authoritative naming practices. Passing refers not only to the social or lived phenomenon of border crossings. Like more generalised definitions of the word passing - that is, that 'which passes away or elapses; transient, fleeting' $(O E D)$ - the definition of passing as a lived performance speaks to and is enabled by a transient context. New technologies of vision and of sound enabled speedy communication across time and space and transformed how people saw themselves and each other. While such technologies assisted in the identification and regulation of individual behaviour as well as the classification of individuals according to knowable groups (race, ethnicity, gender, age, and so on), passing was one strategy that could be used, especially by those disadvantaged by race or ethnicity, to avoid such classifications. In this volume, Pamela Caughie refers to a modern dynamic, a process that relied on the identificatory structures that came with late modernity. For Caughie, passing narratives published at the turn of the twentieth century complicated the role race played in an American modernity characterised by technological transformation.

As I have argued elsewhere, passing not only comes into being through individual awareness and uses of forms of communication; it also enacts transport itselfand the term passing articulates this elusive movement. Figurations of passing that is, attempts to name or narrate passing as a transient phenomena - are, not surprisingly, characterised by gaps, erasures and other explanatory failures. If

6 Ibid., p. 247.

7 Wikipedia lists two definitions of 'passing' in terms of the usage explored here. While the first is a more general category that refers to passing in terms of movement across a wider variety of social groups and begins with the example of a suicide bomber passing as a Jew in order to enter a Jewish hotel, nearly all of its other references are drawn from a US context (see <http://en.wikipedia.org/wiki/Passing_(sociology)>, viewed 11 March 2010). The other Wikipedia reference is to passing as a racial identity in US history $(<$ http:// en.wikipedia.org/wiki/Passing_(racial_identity)>, viewed 11 March 2010). 
the act of passing is about avoiding the categorisation made possible by modern systems of surveillance, stories about passing - that is, the representation of passing — refer to a necessarily unstable act. ${ }^{8}$ To attempt to name the passer is to pinpoint something that eludes or resists classification. Passing can, in this sense, be compared with the role of metaphor in language. As early modern scholar Patricia Parker argues, metaphor is a rhetorical term that speaks to a human desire to gain authority, through naming, over something that is necessarily elusive or free floating. Referring to Dr Johnson's definition of metaphor as 'the application of a word to an use to which, in its original use, it cannot be put', Parker argues that metaphor troubles the proper order and meaning of things:

Metaphor in these discussions is always on the margins of discourse (Barbara H. Smith), outside the city walls, and its potential incivility generates concern for its 'mastery' (Aristotle), moderation (Quintilian), or 'proper management' (Blair). But the rule of metaphor contains, as an ambiguous genitive, that mastery's threatened opposite, the rule of metaphor as a Lord of Misrule. As Derrida suggests, the 'master' of metaphor may himself be transported. ${ }^{9}$

This description of metaphor via tropes of exclusion and inclusion, order and disorder is applicable to the passing act. Langston Hughes' eponymous poem Passing (1950) evokes a city that contains visible and invisible walls among literal and metaphorical lines of communications. While the poem refers to passing as the crossing of the 'color line' that separates racially marked Harlem from other parts of New York City, the waves of sound that come through the radio seem to engender transgression:

On sunny summer Sunday afternoons in Harlem

when the air is one interminable ball game

and grandma cannot get her gospel hymns

from the Saints of God in Christ

on account of the Dodgers on the radio,

on sunny Sunday afternoonst

when the kids look all new

and far too clean to stay that way

and Harlem has its

washed-and-ironed-and-cleaned-best out

the ones who've crossed the line

to live downtown

miss you,

8 Rooney, Monique 2001, 'Grave endings: the representation of passing', Australian Humanities Review, September, viewed 28 February 2001, <http://www.australianhumanitiesreview.org/archive/IssueSeptember-2001/rooney2.html>

9 Parker, Patricia 1987, Literary Fat Ladies: Rhetoric, gender, property, Methuen, London, pp. 37-9. 
Harlem of the bitter dream, since their dream

has come true.

That a Harlem 'grandma' listens to Christian preachings on the radio, her grandchild listens to Jackie Robinson's heroic exploits in Dodger Stadium, while others have moved to Manhattan's white side suggests that cross-racial identifications are already imagined and engendered through technological communications that are not completely contained through racial segregation. Hughes was an African-American poet who lived in New York and began writing during the early 1920s, a time when the rise of an educated (including African-American) middle class, as well as the development of mainstream and specialised publishing houses, enabled the publication of African-Americanauthored passing-for-white stories. His specialised or in-group understanding of the phenomenon is tacitly communicated when passing is referenced in the plural ('the ones who have crossed') rather than identified as a random, individual act. While passing is a 'dream come true', an escape from racially segregated Harlem, it is also a social transgression that takes place among other, less stigmatised or fraudulent crossings.

That Hughes' poem associates passing-for-white with other more diffuse crossings suggests that passing can be understood as a term with a specific etymology and social history and as a metaphor that transports and can be transported to other contexts. In recent years, and especially within an academic context, scholarship about passing has diversified and proliferated to include a broad array of ethnic, gendered and sexual border crossings. ${ }^{10}$ Such scholarship has, however, largely been generated from and focused on a US context. As a topic that draws attention to identities in flux, passing can also be identified in broader, cultural contexts. In recent years - especially as discussed in the work of prominent Anglo-American theorists Judith Butler, Eve Sedgwick and Barbara Johnson ${ }^{11}$ _ passing has played an important part in intellectual discussions about deconstruction, post-structuralism, queer and other minority group politics and has had an effect beyond the American academy. Discussions of passing have also featured in more populist debates about multiculturalism, border control and challenges to traditional gender and sex roles. These more

\footnotetext{
10 See, for example: Ginsberg, Elaine K. (ed.) 1996, Passing and the Fictions of Identity, Duke University Press, Durham, NC, and London, UK; Kroeger, Brooke 2003, Passing: When people can't be who they are, Public Affairs, New York; Sánchez, María Carla and Schlossberg, Linda 2001, Passing: Identity and interpretation in sexuality, race, and religion, New York University Press; Nakamura, Lisa 1995, 'Race in/for cyberspace: identity tourism and racial passing on the internet', Works and Days 25/26, vol. 13, nos 1-2, pp. 181-93.

11 See Johnson, Barbara 1993, 'Lesbian spectacles: reading Sula, passing, Thelma and Louise, and The Accused', in Marjorie Garber, Jann Matlock and Rebecca Walkowitz (eds), Media Spectacles, Routledge, New York, pp. 160-6; Butler, Judith 1993, 'Passing/queering', Bodies That Matter, Routledge, New York, pp. 16785; Sedgwick, Eve 1990, Epistemology of the Closet, University of California Press, Berkeley.
} 
recent controversies highlight passing's continued topicality but they wrest the theme from a racial and specifically national (especially US) context. Given this development, how can the concept of passing provide fresh understandings of contemporary culture and identity?

From historical cases of passing and fictional depictions of the act to theoretical and populist preoccupations with the passer as a border crosser, engagements with 'passing' consistently explore identity not as an a priori, a 'to-be-given', but as a generative topic that enables debate. It is this conception of passing that is central to the essays collected here. In exploring the many facets and faces of passing, the contributors explore the topic's continued relevance. By engaging with passing as a lived, social phenomenon, this collection draws attention to social inclusions and exclusions that generate questions about the authenticity and inauthenticity, the visibility and invisibility of modern identities and provide ways to think about the role of authorship and narrative in modernity, within and outside the West. In order to reproduce the contingent and the metaphorical implications of passing - a theme that has a discursive as well as a lived history - this collection begins with essays that frame passing in terms of US history. It then moves forward to essays that engage with passing outside this socio-historical context.

The first two essays read examples of passing in the context of a complex, present-day United States. In her essay, 'Passing Strange and post-civil rights blackness', Gayle Wald compares a recent Broadway musical, which explores American race relations through a protagonist who travels outside US borders, with early twentieth-century passing-for-white narratives. Her analysis of Passing Strange - a musical that cannily references passing as an identity performance in a range of texts ranging from Shakespeare's Othello to James Baldwin's 'Giovanni's Room'-looks at the self-conscious representation of black identity and the way in which race is inextricably tied to gender and sexuality for a 'post civil-rights' generation. Passing Strange engages with how educated, middle-class members of this generation have inherited political and material gains that are experienced as inauthentic in relation to continued identifications of race as a category understood to be performative. Wald explores the significance of 'passing for black' as performed through Passing Strange's lead character, the 'Youth'. The nature of the Youth's performanceone that raises questions about sex and gender, as well as race-becomes most obvious once he leaves Los Angeles to travel to Amsterdam, where he finds that white-European views of African-Americans are based on images gleaned from hip-hop and other popular-culture exports.

In the case of Passing Strange, the act of 'passing for black' inverts the idea that passing entails a movement from disadvantage to social privilege and speaks to the marketability of victimhood in contemporary US culture. Likewise, Caroline 
Hamilton's analysis of the passing performance of Laura Albert - an aspiring author who created a fake identity in the form of a trans-gender ex-prostitute and recovering heroin addict, J. T. Leroy, in order to market and publish a book - speaks to the dynamic and performative possibilities of authorship. 'Passing for an author: the strange case of J. T. Leroy' draws on theories of Michel Foucault and Roland Barthes to argue that Albert created Leroy in order to pass as an author 'she could not otherwise be'. In her deft analysis of this literary hoax, Hamilton elucidates a case that exemplifies how perceptions of the author are based on a false view of her singularity and authenticity in a way that distorts the multiple and shifting role of the author in the digital age. In doing so, Hamilton reinforces the connections, rather than differences, between Laura Albert and her fictional creation, J. T. Leroy.

Wald's and Hamilton's essays draw attention to the relevance of passing in a contemporary US context in which the proliferation of simulated images through multimedia and other platforms - continues to generate anxieties about authority and authenticity. The role of the simulated image - the imitationis also central to my contribution, 'What passes in Imitation of Life (1959)?', in which I revisit the significance of a racial-passing plot in a Hollywood melodrama that has been the discussion of much scholarly debate. Drawing on Director Douglas Sirk's understanding of melodrama as an ancient form in which the visual body is essential to the communication of meaning, I analyse his melodrama, Imitation of Life, for connections it makes between passing, acting and film-making. I focus on the intersection of Imitation of Life's race and sexual passing plots through analysis of its Oedipal family romance in which a mixed-race child imitates the performance of her white, surrogate mother. My essay investigates the tension between what Sirk says about his film and what the film presents, including the under-acknowledged role of Sirk's producer, Ross Hunter, particularly the part he played in screening the film's more tacit passing plots. Through a two-pronged approach — which explores the film's passing plots via the onscreen and off-screen performances of the film's actors, director and producer-I look at the importance of the visual as a medium that needs to be understood in terms of its productive gaps and expressive failures.

Kate Lilley's 'Mary Carleton's false additions: the case of the "German Princess"' looks at an identity performance outside a twentieth-century, American context and engages with the generative effects of passing as a metaphor for social and textual mobility in Restoration London. The case of Mary Carleton, as Lilley elucidates it, reveals the passer as an ingenious shape-shifter, a trickster figure, whose success is enabled partly through her ability to mirror the trickery of others. Suggesting the centrality of imitation to the passer's modus operandi, Lilley's reading of Carleton's 'false' presentation of herself as an aristocrat, a 'German Princess', shows how Carleton's performance doubled itself through the 
literature that proliferated about her. That Carleton eventually gained notoriety, and in some circles became a celebrity, demonstrates Carleton's ingenuity and talent; while Carleton passes as a 'German Princess', she also performs a version of that which she already is: 'quality without an estate.' The case of Mary Carleton, as rendered in Lilley's essay, thus speaks to a contradictory logic still at play in recent passing narratives. That is, the passer's ostensibly ingenuous passing act is successful because it dissembles - it falsely mirrors and takes duplicitous advantage of - social assumptions and expectations. Carleton's 'passing for quality' operates through her talent for self-styling in a society in which such self-invention, and the opportunities it creates for upward mobility, is a source of fascination and anxiety. For a woman, as Lilley argues, however, such opportunism is associated with (masculine) agency. In this respect, Carleton's performance constituted her as a 'hermaphrodite', a master-mistress of her own fated destiny.

Pamela L. Caughie discusses passing in relation to modern anxieties about imitation and, more particularly, questions about the meaning of subjectivity in the era of early and mid-twentieth-century mass production. In doing so, Caughie challenges popular and scholarly assumptions that equate knowing with seeing. Drawing on the work of Walter Benjamin, Theodor Adorno and Georg Simmel for her essay, 'Audible identities: passing and sound technologies', Caughie asks what it means to 'conceive identities as audible rather than visual'. In doing so, and building on her theory of passing as a wave or 'a transfer of energy from point to point', Caughie looks at the way modern forms of communication (the radio, the phonograph and the telephone) divorced voice from sight, and the recorded from the live body, to produce not just a new, technologically mediated sound but an embodied voice that is distinctive to the modern technologies that produce it. Proposing this argument as one that offers "possibilities for re-imagining "passing" as other than erasure, invisibility, appropriation or blackface', Caughie turns to a discussion of how race and class distinctions figure in technologies of voice production. Caughie argues that from the use of racial voices for Hollywood to the BBC's production of a 'classless' English accent, the 'new aurality' of the early twentieth century produced its own sound and, in doing so, troubled the boundary between original and copy, live and recorded representation.

The final section of the issue takes notions of passing, crossing and imitation beyond the framework of US and European culture and history. Vera Mackie's 'Necktie nightmare: narrating gender in contemporary Japan' uses an autobiographical narrative of gender transitioning, Nômachi Mineko's O-kama dakedo OL yattemasu (I'm Queer but I'm an Office Lady), which explores how identifying passing's 'local context can teach us about the particular fault lines and tensions concerning identity and difference in that site'. A Japanese office- 
worker's gender crossing from male to female entails not only changes in dress and deportment but choosing between personal pronouns that depend on 'the gender of the speaker, the formality of the utterance, and the relationship between speaker and hearer'. In Japan, the nation-state's racialised concerns about the reproduction of the population have put greater weight on traditional expectations of heterosexual marriage at the same time that legal and medical prohibitions of gender transitioning have relaxed. And the implications of shifting gender have particular implications in a culture in which masculinity and birth order remain cultural capital to have and lose. However fraught, Nômachi's autobiography remains a story of liberation.

The issue ends with an interview with Anna Broinowski, director of the critically acclaimed film Forbidden Lies (2007). Its subject is Norma Khouri, an American citizen who passed herself off for several years as a refugee with a story to tell about honour killing in Jordan. My interview with Broinowski explores the importance of passing to understandings of illegal border crossings, contemporary attitudes to the Middle East and the role of the celebrity author and the film-maker in fabrications of identity. The interview explores the film's reading of Norma as a 'consummate performer' ... 'a Scheherazade of the digital age' as Broinowski articulates what it means to capture Norma's spin-making and shape-shifting on screen. Here, Broinowski's discussion of her failure to find a 'real' or 'authentic' Norma enables a discussion of the limits and possibilities of film-making. Like others represented in this volume, Norma is a passer whose failure and success cannot simply be attributed to her single-minded opportunism and transgression. As Broinowski reminds us, we 'have all been complicit in constructing the environment which had enabled her to thrive'. 